\title{
Early Development of Neuronal Activity in the Primate Hippocampus In Utero
}

\author{
Roustem Khazipov, ${ }^{1}$ Monique Esclapez, ${ }^{1}$ Olivier Caillard, ${ }^{1}$ Christophe Bernard, ${ }^{1}$ Ilgam Khalilov, ${ }^{1}$

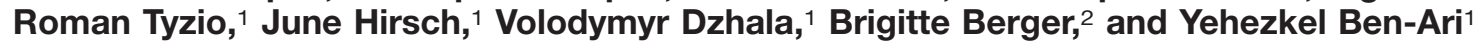 \\ 1/nstitut de Neurobiologie de la Méditerranée/Institut National de la Santé et de la Recherche Médicale (INSERM) U29, \\ Luminy, 13273 Marseille, France, and 2INSERM U106, Hopital de la Salpetriere, 75013 Paris, France
}

\begin{abstract}
Morphological studies suggest that the primate hippocampus develops extensively before birth, but little is known about its functional development. Patch-clamp recordings of hippocampal neurons and reconstruction of biocytin-filled pyramidal cells were performed in slices of macaque cynomolgus fetuses delivered by cesarean section. We found that during the second half of gestation, axons and dendrites of pyramidal cells grow intensively by hundreds of micrometers per day to attain a high level of maturity near term. Synaptic currents appear around midgestation and are correlated with the level of morphological differentiation of pyramidal cells: the first synapses are GABAergic, and their emergence correlates with the growth of apical dendrite into stratum radiatum. A later occurrence of glutamatergic synaptic currents correlates with a further differentiation of the axodendritic tree and the appearance of spines. Relying
\end{abstract}

on the number of dendritic spines, we estimated that hundreds of new glutamatergic synapses are established every day on a pyramidal neuron during the last third of gestation. Most of the synaptic activity is synchronized in spontaneous slow $(\approx 0.1 \mathrm{~Hz})$ network oscillations reminiscent of the giant depolarizing potentials in neonatal rodents. Epileptiform discharges can be evoked by the $\mathrm{GABA}(\mathrm{A})$ receptor antagonist bicuculline by the last third of gestation, and postsynaptic $\mathrm{GABA}(\mathrm{B})$ receptors contribute to the termination of epileptiform discharges. Comparing the results obtained in primates and rodents, we conclude that the template of early hippocampal network development is conserved across the mammalian evolution but that it is shifted toward fetal life in primate.

Key words: hippocampus; primate; fetus; development; GABA; glutamate; epilepsy
Most of our knowledge on neuronal activity in a developing brain comes from studies on lower mammals. These studies have demonstrated that neurons establish synapses from the early developmental stages and that the developing networks generate particular patterns of spontaneous coordinated neuronal activity in virtually all peripheral and central structures studied so far (BenAri, 2001). In the rat hippocampus, immature pyramidal neurons start to receive sequentially established GABAergic and glutamatergic synaptic inputs around birth (Tyzio et al., 1999). During the first two postnatal weeks - a period of intense neuronal growth and synaptogenesis-the hippocampal network generates periodic synchronized neuronal discharges, known as giant depolarizing potentials (GDPs) (Ben-Ari et al., 1989). GDPs drive synchronized oscillations of intracellular calcium and provide conditions for Hebbian plasticity in developing synapses (Leinekugel et al., 1997; Garaschuk et al., 1998).

In contrast to lower mammals, in primates the functional development of the hippocampus, or as a matter of fact any cortical structures, is unknown. Morphological studies have shown that comparable stages of hippocampal development occur much earlier in primates than in rodents with most of the devel-

\footnotetext{
Received May 14, 2001; revised Sept. 5, 2001; accepted Oct. 2, 2001.

We thank G. Germain for performing the cesarean sections, R. Cossart for the help in analyzing data, P. Rakic, G. Buzsaki, G. L. Holmes, J. L. Gaiarsa, and R. Cannon for critical reading, and G. Medina for the help in preparing this manuscript.

R.K. and M.E. contributed equally to this work.

Correspondence should be addressed to Dr. Roustem Khazipov, Institut de Neurobiologie de la Méditerranée/Institut National de la Santé et de la Recherche Médicale, U29 163, Route de Luminy, B. P. 13, Marseille 13273, France. E-mail: khazipov@inmed.univ-mrs.fr.

Copyright (C) 2001 Society for Neuroscience $\quad 0270-6474 / 01 / 219770-12 \$ 15.00 / 0$
}

opmental process taking place in utero both in human (Humphrey, 1967; Paldino and Purpura, 1979; Kostovic et al., 1989; Arnold and Trojanowski, 1996; Hevner and Kinney, 1996) and nonhuman primates (Nowakowski and Rakic, 1979; Duffy and Rakic, 1983; Eckenhoff and Rakic, 1991; Seress and Ribak, 1995; Berger and Alvarez, 1996; Berger et al., 1997, 1999). Moreover, a hippocampal-dependent form of recognition memory has been recently reported in human and monkey babies soon after birth (Bachevalier et al., 1993; Bachevalier and Mishkin, 1994; Pascalis and de Schonen, 1994; Pascalis and Bachevalier, 1999) raising the possibility that the hippocampal network may be operational before birth. However, because electrophysiological recordings have not been performed in the fetal primate brain, several fundamental questions remain unanswered, namely, when do hippocampal neurons start to communicate via synaptic connections and when do early patterns of the coordinated network activity emerge? Determining these issues is essential to understand not only hippocampal development, but also developmental pathologies associated with the hippocampus, including epilepsy. This information is also important for understanding phylogenetic aspects of hippocampal development and for using lower mammals as a model of human brain development.

In the present study, we have performed patch-clamp recordings from pyramidal cells and interneurons in hippocampal slices of six cynomolgus monkey fetuses delivered by cesarean section during the second half of gestation [embryonic day 85 (E85) to E154, term $165 \mathrm{~d}$ ], at a time when neurogenesis is complete in the hippocampus (Rakic and Nowakowski, 1981). Biocytin-filled neurons were reconstructed to correlate the extent of dendritic and axonal development with the neuronal activity. The principal 
conclusion of this study is that in primates, neuronal activities emerge early in utero and that there is a rapid pace of maturation that enables the neurons, essentially silent at the beginning of midgestation, to have all the morphological and physiological properties required to generate network-driven endogenous and epileptiform activities before birth.

\section{MATERIALS AND METHODS}

Preparation of animals and tissue. The study was conducted under the approval and guidelines of the Ethical Committee of the Institut National de La Recherche Agronomique Primate Center at Jouy-en-Josas, France. Six cynomolgus monkey (Macaca fascicularis) fetuses of ages E85, E105, E109, E119, E134, and E154 (term 165 d) were delivered by cesarean section under anesthesia with $10 \mathrm{mg} / \mathrm{kg}$ ketamine and $1 \mathrm{mg} / \mathrm{kg}$ diazepam. The fetuses were intracardially perfused with cold $\left(2-4^{\circ} \mathrm{C}\right)$ oxygenated $\left(95 \% \mathrm{O}_{2}\right.$ and $\left.5 \% \quad \mathrm{CO}_{2}\right)$ modified artificial CSF (ACSF) (Hirsch et al., 1996). The brains were quickly removed and immersed for dissection into ice-cold oxygenated standard ACSF that contained (in mM): $126 \mathrm{NaCl}, 3.5 \mathrm{KCl}, 2.0 \mathrm{CaCl}_{2}, 1.3 \mathrm{MgCl}_{2}, 25 \mathrm{NaHCO}_{3}, 1.2 \mathrm{NaH}_{2} \mathrm{PO}_{4}$, and 11 glucose. Transverse hippocampal slices $(400-\mu \mathrm{m}$-thick) were cut with a Leica VT 1000E (Nussloch, Germany) tissue vibroslicer, transferred to a beaker containing oxygenated ACSF and kept at room temperature $\left(20-22^{\circ} \mathrm{C}\right)$ for at least $1-2 \mathrm{hr}$ before use. Slices were recorded in a submerged chamber perfused with oxygenated ACSF $\left(30-32^{\circ} \mathrm{C}\right)$.

Electrophysiology. Patch-clamp recordings were performed using Axopatch 200 (Axon Instruments, Union City, CA) and EPC-9 (HEKA Elektronik, GmbH, Lambrecht/Pfalz, Germany) amplifiers. Cells were either recorded blindly or under visual control using infrared microscopy, with microelectrodes of 7-10 $\mathrm{M} \Omega$ resistance when filled with a solution containing (in mM): $135 \mathrm{~K}$ gluconate, $2 \mathrm{MgCl}_{2}, 0.1 \mathrm{CaCl}_{2}, 1$ EGTA, 2 $\mathrm{Na}_{2}$ ATP, and 10 HEPES, pH 7.25, osmolarity $270-280 \mathrm{~mol} / \mathrm{kg}$. The cells were identified as neurons based on the following criteria: action potential firing in response to a depolarizing step, presence of a synaptic activity (except for "silent" neurons), and morphology. Usually the cells were held at -70 or $0 \mathrm{mV}$ to record glutamatergic and GABAergic synaptic currents, respectively. Electrical stimulation $(0-80 \mathrm{~V} ; 10-30$ $\mu$ sec; delivered at $0.02-0.05 \mathrm{~Hz}$ ) was provided by a bipolar electrode placed in the stratum radiatum. All the neurons were filled with biocytin $(0.4 \%)$ for post hoc morphological analysis. Electrophysiological data were analyzed using Acquis (G. Sadoc, Paris, France), Clampex (Axon Instruments), and Origin (Microcal Software, Northampton, MA).

Morphology. All the recorded slices were processed for biocytin-filled neuron detection. In addition, some hippocampal slices were collected immediately after slice preparation, for immunohistochemistry. The slices were fixed overnight at $4^{\circ} \mathrm{C}$ in a solution containing $4 \%$ paraformaldehyde in $0.1 \mathrm{M}$ phosphate buffer (PB), pH 7.4. After fixation, slices were rinsed in $\mathrm{PB}$, cryoprotected in sucrose for $16 \mathrm{hr}$, and quickly frozen on dry ice. The detection of biocytin-filled neurons was performed on unsectioned slices. To neutralize an endogenous peroxidase, slices were pretreated for $30 \mathrm{~min}$ in $1 \% \mathrm{H}_{2} \mathrm{O}_{2}$. After several rinses in $0.1 \mathrm{M} \mathrm{PBS}, \mathrm{pH}$ 7.4, slices were incubated for $24 \mathrm{hr}$ at $4^{\circ} \mathrm{C}$ in $1: 100$ avidin-biotinylated peroxidase complex diluted in PBS containing 0.3\% Triton X-100. After $30 \mathrm{~min}$ rinses in PBS, slices were processed with $0.06 \%$ 3,3'diaminobenzidine tetrahydrochloride (DAB; Sigma, St. Louis, MO) and $0.006 \% \mathrm{H}_{2} \mathrm{O}_{2}$ diluted in PBS, rinsed, mounted on gelatin-coated slides, and coverslipped in an aqueous medium (Crystal/Mount; Biomeda, Foster City, CA).

Among 147 recorded neurons, 100 neurons were morphologically identified including 28 CA1 pyramidal cells, 27 CA3 pyramidal cells, 31 hippocampal interneurons, 10 pyramids and interneurons in subiculum and neocortex, and 6 granular cells. 25 CA3 and 20 CA1 pyramidal cells with a complete labeling of dendritic and axonal arbors were reconstructed for morphometric analysis using the Neurolucida system (MicroBrightField Inc., Colchester, VT). All the spines observed along the dendritic arborization of pyramidal cells were marked for further numerical analysis. Statistical analysis of the morphometric data was performed using Origin software (Microcal, Northampton, MA). Morphometric parameters from pooled CA1-CA3 pyramidal cells were fitted with a Boltzmann function: $y=A_{\min }+\left(A_{\max }-A_{\min }\right) /(1+$ $\exp ((x-x 0) / d x))$, with $A_{\text {min }}$ fixed to 0 . The rate of development of axonal and dendritic lengths, together with the increase in the number of spines, were deduced from the derivative of the fits.

Immunohistochemistry. The slices to be processed for histochemistry were resectioned $(40 \mu \mathrm{m})$ on a cryostat. Sections were rinsed in $0.01 \mathrm{M}$ PBS, $\mathrm{pH} \mathrm{7.4,} \mathrm{(1 \times} \mathrm{PBS),} \mathrm{collected} \mathrm{sequentially} \mathrm{in} \mathrm{tubes} \mathrm{containing} \mathrm{an}$ ethylene glycol-based cryoprotective solution and stored at $-20^{\circ} \mathrm{C}$ until processing. For each animal, adjacent sections were processed for immunohistochemistry with unlabeled antibodies that are specific to GAD-65 (mouse monoclonal GAD-6) and GAD-67 (rabbit polyclonal K2) and standard avidin-biotin-peroxidase immunolabeling methods (Vectastain Elite rabbit IgG kit; Vector Laboratories, Burlingame, CA) as described previously (Esclapez et al., 1994).

\section{RESULTS}

\section{The second half of gestation: a period of intensive growth of pyramidal cells}

The second half of gestation was characterized by an intensive morphological differentiation of pyramidal cells, including the growth and ramification of axonal and dendritic arbors and the formation of spines. As a result, pyramidal cells that were very immature with little neuritic extensions at midgestation were endowed with a high level of differentiation 1 month before birth (Fig. 1, Table 1).

At midgestation (E85), immature pyramidal neurons displayed a relatively long axonal process running in stratum oriens but only short apical dendrites with few branches and little or no basal dendrites. Apical dendrites were mainly restricted to the cell body layer in CA1 but entered the proximal part of stratum radiatum in CA3. Many dendritic and axonal processes ended with growth cones.

At E105-E109, the apical dendrites extended through stratum radiatum to lacunosum moleculare; the basal dendrites penetrated and ramified in stratum oriens. At this stage, the first dendritic spines were observed. Axons of CA3 pyramidal cells gave rise to numerous recurrent and Schaffer collaterals; CA1 pyramidal cells emitted many local axonal branches running in strata oriens and radiatum as well as projections to the subiculum.

At E134 and E154, pyramidal cells had well differentiated dendritic and axonal arbors that extended through all their proper layers. The densely ramified apical dendrites crossed the stratum lacunosum moleculare up to the hippocampal fissure. Apical and basal dendrites were covered with spines.

A morphometric analysis of the total length and the number of branches for dendrites and axons of pyramidal cells from CA3 and CA1 revealed a progressive increase of all these parameters from E85 to E134. From E134 to E154, the length and number of dendritic and axonal branches did not change significantly (Fig. 2, Table 1). The number of spines increased continuously from E105 onward to attain some 7000 spines per pyramidal cell before birth (E154) (Fig. 2, Table 1). The density of spines at E154 was 55 spines $/ 100 \mu \mathrm{m}$ and matched the one observed in the neonate rhesus monkey (47/100 $\mu \mathrm{m}$; Seress and Ribak, 1995). Thorny excrescences were not observed on CA3 pyramidal cells, confirming that the complex mossy fiber synapses mature mainly after birth (Vijayan, 1986; Seress and Ribak, 1995). Thus, the morphological differentiation of the pyramidal cells in the primate hippocampus occurs essentially during the second half of gestation, and the pyramidal cells already attain a high level of maturity before birth.

\section{The sequential expression of GABA and glutamatergic synaptic currents correlates with the morphological maturation of the pyramidal cells}

Synaptic activity was observed in hippocampal pyramidal neurons starting from midgestation, and the expression of synaptic currents was highly correlated with their degree of morphological differentiation (Fig. 3, Table 1). Based on the expression of 


\section{E 105}

E 85

CA1

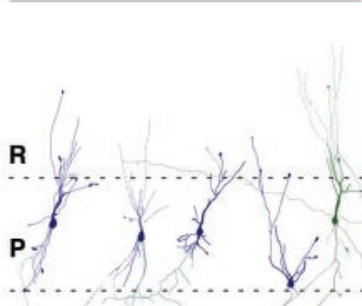

O

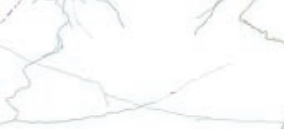

134
CA3

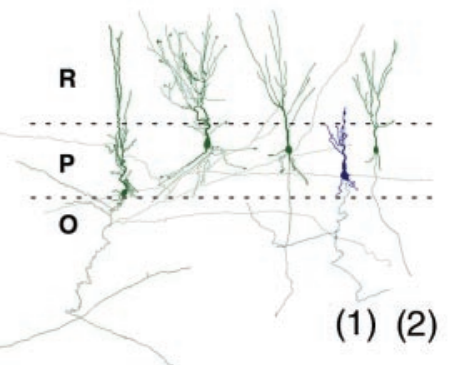

CA1

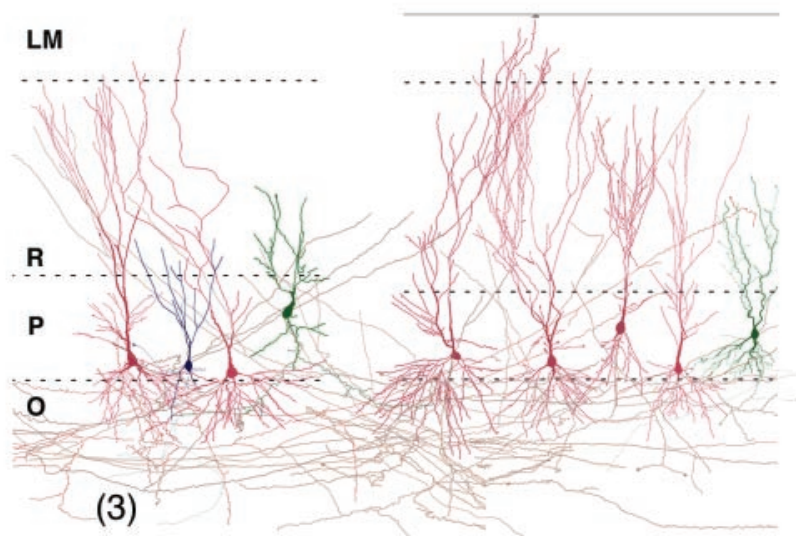

E 154

CA3

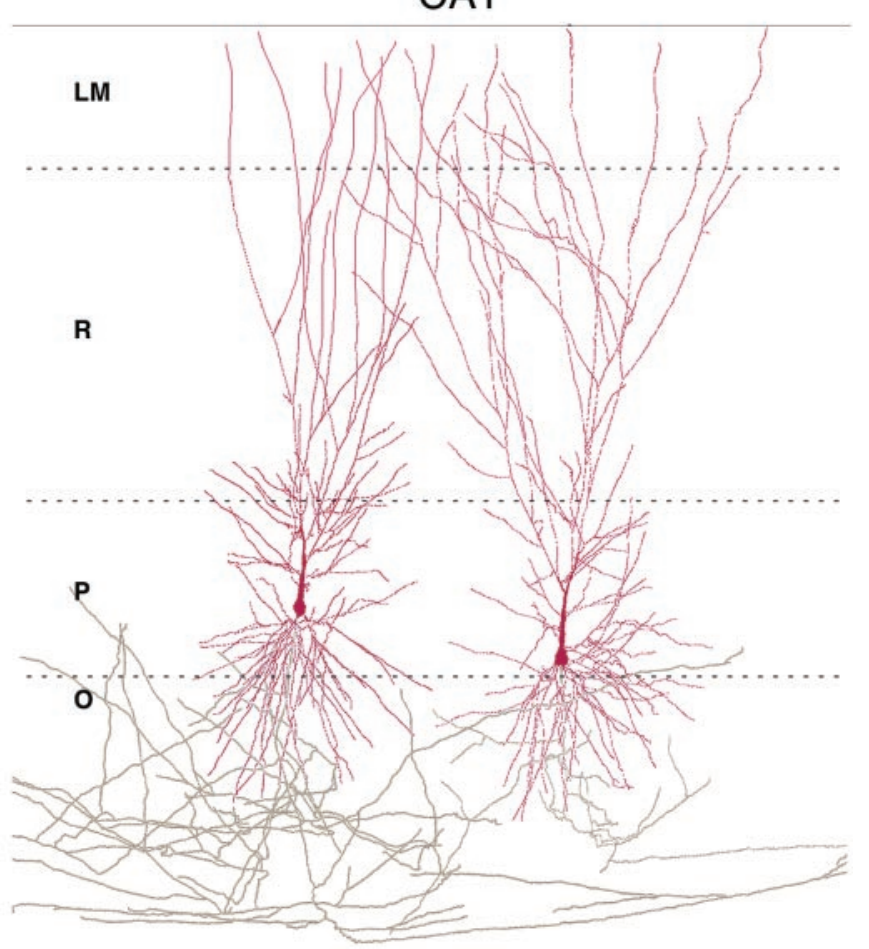

Figure 1. Morphological differentiation of pyramidal cells in the cynomolgus monkey hippocampus during the second half of gestation. Reconstruction of biocytin-filled pyramidal cells in CA1 and CA3 hippocampal subfields at various ages in utero (E85-E154). Note an intensive growth of the pyramidal cells that reach a high level of morphological differentiation at E134, 1 month before birth. $O$, Stratum oriens; $P$, pyramidal cell layer; $R$, stratum radiatum; $L M$, stratum lacunosum moleculare; the dashed lines indicate the limits between layers, and the solid line indicates the hippocampal fissure. Axons ( gray), color of the dendritic arborization indicates the expression of synaptic currents (blue, silent; green, GABA-only; red, GABA + glutamate neurons). Electrophysiological recordings from neurons 1-3 are shown on Figure $3 A$. Scale bar, $100 \mu \mathrm{m}$.

GABAergic and glutamatergic postsynaptic currents (PSCs), pyramidal cells could be divided into three groups:

Synaptically "silent" neurons did not have functional synaptic inputs because no spontaneous activity was recorded in these cells and electrical stimulations of afferent pathways did not evoke any synaptic currents. Morphometric analysis of these neurons showed that synaptically silent neurons had short and poorly ramified axonal and dendritic processes. The dendrites were nonspiny and restricted to the pyramidal cell layer and the inner part of stratum radiatum (Figs. 1, 4B). These neurons were mainly observed in the CA1 region at midgestation (Fig. 1).
"GABA-only" neurons had only GABAergic, but not glutamatergic, synaptic inputs. All evoked and spontaneous PSCs in these neurons had a reversal potential near $\mathrm{ECl}-$ and were abolished by the $\operatorname{GABA}(\mathrm{A})$ receptor antagonist bicuculline (Fig. 3A). "GABA only" neurons were observed between E85 and E109 and were more differentiated than "silent" ones. They had significantly longer neuronal processes and their apical dendrites (still nonspiny) penetrated deeper into the stratum radiatum (Fig. 4C). Interestingly, at midgestation, GABAergic terminals immunolabeled for GAD65 or GAD67 were found in strata radiatum and oriens but not in stratum pyramidale (Fig. $4 A$ ). 
"GABA + glutamate" neurons had both GABA and glutamatergic synaptic inputs. These were the most differentiated neurons, which were first observed at E105. From E119 onward, all the recorded pyramidal cells exhibited both GABAergic and glutamatergic PSCs (Fig. 3C). The dendritic and axonal arbors of GABA + glutamate neurons were twofold to threefold more developed when compared with GABA-only cells from the same age (E105-E109) (Figs. 3B, 4D,E). The emergence of glutamatergic PSCs was correlated with an intensive outgrowth of local axonal recurrent and Schaffer collaterals of pyramidal cells, a morphological substrate for connections between pyramidal cells (Figs. 1, 3B), and was also concomitant to the occurrence of the first dendritic spines (Fig. $4 F-I$ ). Interestingly, the appearance of glutamatergic PSCs also coincided with the emergence of the first network-driven events, suggesting that early glutamatergic inputs are provided by an intrahippocampal circuitry rather than by external inputs (see below). In the present study, none of the recorded neurons only had a glutamatergic synaptic input.

Quantitative analysis of the morphometric parameters of silent, GABA-only, and GABA + glutamate pyramidal neurons demonstrated clear differences between the three groups (Table 1, Fig. $3 B$ ). Whereas the size of the somata showed no difference between the three groups, the total length of dendrites and axons was significantly higher in the GABA + glutamate group as compared with the GABA-only and silent groups. GABA + glutamate neurons were the only ones to have spines. When the total number of neurons with GABA-only or GABA + glutamate synapses are plotted according to the developmental age (Fig.

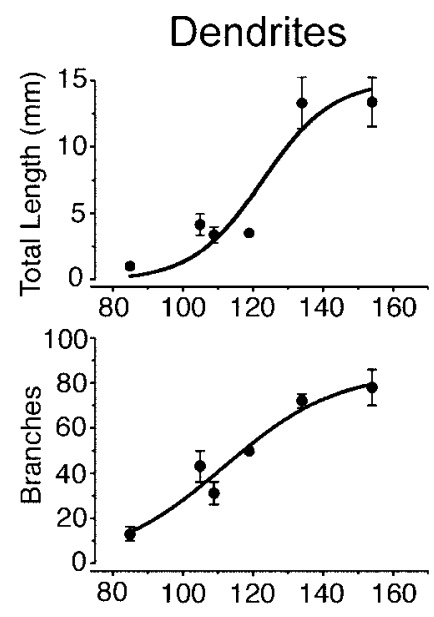

Age in utero(days)
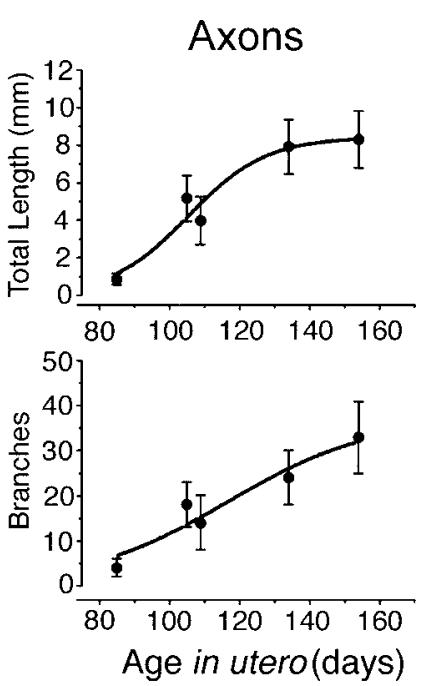

Spines

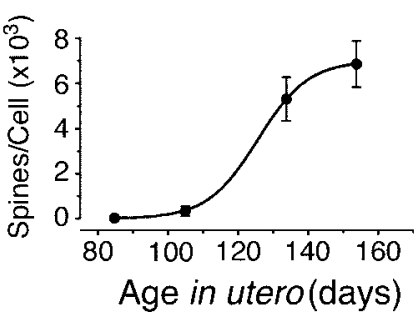

Figure 2. Morphometric parameters of the pyramidal neurons as a function of age in utero. Pooled data from CA1 and CA3 pyramidal neurons (mean \pm SEM; see also Table 1); age dependence of morphometric parameters has been fitted with a Boltzmann function.
$3 C)$, it becomes apparent that GABA PSCs are present in half of the neurons at $\sim \mathrm{E} 85$. In contrast, pyramidal neurons have no glutamatergic synapses at that stage. Basing on the Boltzmann fit of the age dependence of the glutamatergic PSC expression, it can be inferred that half of the pyramidal cells receive glutamatergic inputs $\sim 2$ weeks later, at $\sim$ E100. Also note that from E119 onward, all pyramidal neurons possess both types of synapses.

Taken together, these data suggest that functional synapses are established on pyramidal cells at the early stages of their morphological differentiation and that the first GABAergic synapses are established before the glutamatergic ones. GABA and glutamatergic synaptic currents were also recorded in interneurons, but a systematic study of their morphofunctional development was not performed because of the heterogeneity of this population (Freund and Buzsaki, 1996).

\section{Early pattern of synchronized network activity}

The prenatal differentiation of pyramidal cells, as well as of granular cells (Duffy and Rakic, 1983; Eckenhoff and Rakic, 1991) and interneurons (Berger and Alvarez, 1996; Berger et al., 1999), and the early establishment of synaptic connections provides a basis for the in utero emergence of synchronized activities in the hippocampal network. No spontaneous network-driven activity was observed at midgestation (E85; $n=0$ of 12) and seldom close to term (E154; $n=1$ of 10$)$. In contrast, between E105 and E134 the majority of pyramidal neurons $(n=23$ of 38) displayed periodic network-driven events occurring at a frequency of $0.13 \pm 0.04 \mathrm{~Hz}(n=23)$ (Figs. 5, 6). This activity was reminiscent of the so-called GDPs described in the neonatal rat hippocampus (Ben-Ari et al., 1989; Leinekugel et al., 1997). Fetal monkey GDPs displayed the typical features of polysynaptic network driven events: (1) they were synchronously generated in simultaneously recorded neurons ( $n=8$ pairs); (2) they could be evoked in an all-or-none manner by electrical stimulation, the latency being dependent on the stimulus intensity; (3) their frequency was independent of the membrane potential; and (4) they were completely blocked by tetrodotoxin ( $1 \mu \mathrm{M} ; n=3)$. GDPs were synchronously generated in paired recordings from pyramidal cells and interneurons ( $n=6$ pairs) (Fig. 5) and were mediated by synaptically activated GABA(A) and glutamate receptors. As in the rat hippocampus (Ben-Ari et al., 1989), the GDPs were completely blocked by glutamate receptor antagonists CNQX $(10 \mu \mathrm{M})$ and APV $(50 \mu \mathrm{M})(n=8)$ and were transformed to paroxysmal discharges by the $\mathrm{GABA}(\mathrm{A})$ receptor antagonist bicuculline (Fig. 6). In several neurons, the elementary synaptic events could be discriminated, and the analysis revealed a dramatic increase in the frequency of synaptic currents during GDPs: the frequency of GABA and glutamate receptor-mediated postsynaptic currents increased from $1.3 \pm 0.1 / \mathrm{sec}$ to $22 \pm 6 / \mathrm{sec}$ $(n=4)$ and from $3.5 \pm 2 /$ sec to $46 \pm 17 / \mathrm{sec},(n=3)$ respectively (Fig. 5). The total count of synaptic events revealed that $49 \pm$ $10 \%(n=4)$ of GABAergic and $42 \pm 5 \%(n=3)$ of glutamatergic synaptic activity is synchronized in GDPs. Thus, GDPs in the fetal macaque hippocampal slices are generated by GABAergic inputs from interneurons and glutamatergic recurrent collateral synapses, and the synaptic activity is highly synchronized in this early hippocampal pattern during the phase of intensive neuronal growth and synaptogenesis.

\section{Maturation of epileptiform activity}

The prenatal establishment of recurrent collateral synapses provides the conditions for the generation of another type of network 


\begin{tabular}{|c|c|c|c|c|c|c|c|c|c|}
\hline & \multicolumn{9}{|c|}{ CA1 pyramidal cells } \\
\hline & \multicolumn{3}{|l|}{ E85 } & \multicolumn{4}{|c|}{ E105-E109 } & \multirow{2}{*}{ 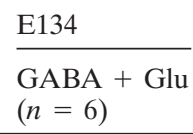 } & \multirow{2}{*}{$\begin{array}{l}\text { E154 } \\
\text { GABA + Glu } \\
(n=3)\end{array}$} \\
\hline & $\begin{array}{l}\text { Silent } \\
(n=4)\end{array}$ & $\begin{array}{l}\text { GABA } \\
(n=1)\end{array}$ & $\begin{array}{l}\text { Total } \\
(n=5)\end{array}$ & $\begin{array}{l}\text { Silent } \\
(n=1)\end{array}$ & $\begin{array}{l}\text { GABA } \\
(n=2)\end{array}$ & $\begin{array}{l}\text { GABA + Glu } \\
(n=3)\end{array}$ & $\begin{array}{l}\text { Total } \\
(n=6)\end{array}$ & & \\
\hline \multicolumn{10}{|l|}{ Cell bodies } \\
\hline Surface $\left(\mu \mathrm{m}^{2}\right)$ & $115 \pm 8$ & 85 & $109 \pm 10$ & 155 & $213 \pm 39$ & $275 \pm 8$ & $234 \pm 30$ & $289 \pm 29$ & $252 \pm 38$ \\
\hline \multicolumn{10}{|l|}{ Total dendrites } \\
\hline Branches & $11 \pm 2$ & 11 & $11 \pm 2$ & 11 & $17 \pm 2$ & $55 \pm 8$ & $35 \pm 10$ & $75 \pm 6$ & $86 \pm 1$ \\
\hline Length $(\mu \mathrm{m})$ & $884 \pm 149$ & 1236 & $954 \pm 135$ & 1584 & $1810 \pm 653$ & $5776 \pm 381$ & $3756 \pm 936$ & $15404 \pm 1206$ & $15316 \pm 1976$ \\
\hline Spines/cell & 0 & 0 & 0 & 0 & 0 & $770 \pm 120$ & $308 \pm 190$ & $6760 \pm 1081$ & $7710 \pm 1050$ \\
\hline \multicolumn{10}{|l|}{ Apical dendrites } \\
\hline Branches & $9 \pm 2$ & 9 & $9 \pm 1$ & 10 & $14 \pm 3$ & $26 \pm 5$ & $20 \pm 4$ & $45 \pm 3$ & $59 \pm 2$ \\
\hline Length $(\mu \mathrm{m})$ & $711 \pm 138$ & 1138 & $796 \pm 137$ & 1301 & $1477 \pm 624$ & $3318 \pm 511$ & $2368 \pm 509$ & $8469 \pm 241$ & $8316 \pm 935$ \\
\hline Spines/cell & 0 & 0 & 0 & 0 & 0 & $640 \pm 30$ & $256 \pm 157$ & $4630 \pm 926$ & $5670 \pm 711$ \\
\hline \multicolumn{10}{|l|}{ Basal dendrites } \\
\hline Branches & $3 \pm 1$ & 2 & $2 \pm 1$ & 1 & $3 \pm 1$ & $29 \pm 5$ & $16 \pm 6$ & $30 \pm 5$ & $28 \pm 1$ \\
\hline Length $(\mu \mathrm{m})$ & $173 \pm 69$ & 98 & $158 \pm 56$ & 283 & $333 \pm 29$ & $2459 \pm 195$ & $1388 \pm 487$ & $6935 \pm 972$ & $7000 \pm 816$ \\
\hline Spines/cell & 0 & 0 & 0 & 0 & 0 & $130 \pm 80$ & $52 \pm 41$ & $2130 \pm 667$ & $2040 \pm 810$ \\
\hline \multicolumn{10}{|l|}{ Axons } \\
\hline Branches & $4 \pm 1$ & 7 & $4 \pm 1$ & 2 & $8 \pm 1$ & $28 \pm 7$ & $17 \pm 6$ & $32 \pm 13$ & $39 \pm 11$ \\
\hline Length $(\mu \mathrm{m})$ & $614 \pm 218$ & 1250 & $741 \pm 211$ & 811 & $3089 \pm 39$ & $7293 \pm 474$ & $4811 \pm 1180$ & $10580 \pm 1517$ & $10438 \pm 2579$ \\
\hline
\end{tabular}

Data are presented as mean \pm SEM ( $n=$ number of cells).

activity-epileptiform discharges. Therefore, in the next series of experiments we studied the development of the epileptiform activity induced by the GABA(A) receptor antagonist bicuculline $(10 \mu \mathrm{M})$ (Figs. 6, 7). At midgestation, no epileptiform activity was observed, in keeping with the large percentage of either silent or GABA-only neurons at this stage. The first epileptiform events in the presence of bicuculline were observed at E105-E109, which coincides with the outgrowth of axonal collaterals of pyramidal cells and the appearance of spines and glutamatergic synaptic currents. The occurrence and severity of epileptiform events increased through gestation in parallel with the development of pyramidal cells and the increase in the number of spines. One month before birth (E134), powerful epileptiform events were observed in all recorded neurons (Fig. 7). Interictal-like events were synchronized by glutamatergic connections because: (1) they reversed near $0 \mathrm{mV}$ and the charge transfer during these events displayed a slope of negative conductance at negative membrane potentials suggesting the contribution of both AMPA and NMDA types of glutamate receptors (Fig. $6 B)(n=4)$ and (2) they were completely blocked by the AMPA and NMDA receptor antagonists CNQX $(10 \mu \mathrm{M})$ and APV $(50 \mu \mathrm{M} ; n=4)$.

During epileptiform discharges, interneurons received a powerful glutamatergic input and fired bursts of action potentials $(n=8)$ (Fig. $6 \mathrm{~A})$, providing the conditions for the activation of GABA(B) receptors. Indeed, at E134 and E154, the epileptiform events were curtailed by an afterhyperpolarization that reversed at $-93 \pm 3 \mathrm{mV}(n=5)$ and displayed an inward rectification that is characteristic of the $\mathrm{GABA}(\mathrm{B})$ receptor-activated potassium conductance (Fig. 8). The GABA(B) receptor antagonist CGP $55812(1 \mu \mathrm{M})$ blocked the outward currents curtailing the epileptiform events and significantly prolonged the discharges $(n=3)$, further suggesting that the activation of the $\mathrm{GABA}(\mathrm{B})$ receptors contributes to the termination of epileptiform discharges. However, at earlier stages, the GABA(B) receptor-mediated currents were not observed (Fig. 6), which is in agreement with a delayed expression of the postsynaptic GABA(B) receptor-mediated inhibition in the rat (Fukuda et al., 1993; Gaiarsa et al., 1995).

Thus, in primate, the hippocampal network becomes capable of generating paroxysmal discharges already in utero, and the progression of the paroxysmal activity likely reflects the development of a recurrent connectivity between pyramidal cells. The observation that epileptiform activities can be generated in the hippocampus already in utero provides additional evidence that the hippocampal network reaches a high level of maturity before birth.

\section{DISCUSSION}

This study provides the first evidence that in primate, a complex hippocampal network capable of generating spontaneous and paroxysmal synchronized activities is already established in utero. It also provides some of the key steps involved in the formation of the network elements, including morphological differentiation of pyramidal neurons, sequential establishment of GABA and glutamatergic synaptic connections, and emergence of synchronized network activity (Fig. 9).

\section{Prenatal maturation of hippocampal primate neurons}

We found that the second half of gestation is a principal period of pyramidal cell differentiation, when dendrites and axons intensively grow and ramify. Whereas pyramidal cells already reach a high level of differentiation 1 month before birth, further growth and remodeling of the axonal and dendritic arbors can probably continue after birth; determining a complete picture of the development of pyramidal cells will require a postnatal study. The majority of dentate gyrus granular cells (Duffy and Rakic, 1983; Eckenhoff and Rakic, 1991) and GABAergic interneurons (Berger and Alvarez, 1996; Berger et al., 1999; Esclapez et al., 1999) also differentiate prenatally. In addition, major extrinsic afferences invade the hippocampus from midgestation and should provide inputs from other brain regions (Berger and Alvarez, 


\begin{tabular}{|c|c|c|c|c|c|c|c|c|}
\hline \multicolumn{9}{|c|}{ CA3 pyramidal cells } \\
\hline \multicolumn{3}{|l|}{ E85 } & \multicolumn{4}{|c|}{ E105-E109 } & \multirow{2}{*}{$\begin{array}{l}\text { E134 } \\
\text { GABA + Glu } \\
(n=6)\end{array}$} & \multirow{2}{*}{$\begin{array}{l}\text { E154 } \\
\text { GABA + Glu } \\
(n=3)\end{array}$} \\
\hline $\begin{array}{l}\text { Silent } \\
(n=1)\end{array}$ & $\begin{array}{l}\text { GABA } \\
(n=6)\end{array}$ & $\begin{array}{l}\text { Total } \\
(n=7)\end{array}$ & $\begin{array}{l}\text { Silent } \\
(n=1)\end{array}$ & $\begin{array}{l}\text { GABA } \\
(n=1)\end{array}$ & $\begin{array}{l}\text { GABA + Glu } \\
(n=7)\end{array}$ & $\begin{array}{l}\text { Total } \\
(n=9)\end{array}$ & & \\
\hline 127 & $88 \pm 11$ & $94 \pm 8$ & 222 & 272 & $227 \pm 27$ & $231 \pm 21$ & $275 \pm 21$ & $265 \pm 28$ \\
\hline 8 & $16 \pm 6$ & $14 \pm 5$ & 10 & 39 & $48 \pm 7$ & $43 \pm 7$ & $70 \pm 5$ & $72 \pm 8$ \\
\hline 385 & $1178 \pm 375$ & $1064 \pm 337$ & 824 & 2560 & $4856 \pm 978$ & $4153 \pm 891$ & $11606 \pm 1914$ & $11798 \pm 1342$ \\
\hline 0 & 0 & 0 & 0 & 0 & $640 \pm 206$ & $382 \pm 217$ & $3860 \pm 870$ & $5970 \pm 920$ \\
\hline 6 & $13 \pm 5$ & $12 \pm 4$ & 5 & 19 & $30 \pm 3$ & $26 \pm 4$ & $45 \pm 4$ & $49 \pm 9$ \\
\hline 290 & $992 \pm 268$ & $891 \pm 247$ & 527 & 1569 & $3507 \pm 687$ & $2960 \pm 643$ & $6619 \pm 1260$ & $6798 \pm 1057$ \\
\hline 0 & 0 & 0 & 0 & 0 & $540 \pm 190$ & $324 \pm 191$ & $2757 \pm 1300$ & $3810 \pm 1230$ \\
\hline 2 & $2 \pm 2$ & $2 \pm 1$ & 5 & 20 & $18 \pm 4$ & $17 \pm 4$ & $25 \pm 2$ & $23 \pm 5$ \\
\hline 95 & $186 \pm 112$ & $173 \pm 96$ & 297 & 991 & $1349 \pm 388$ & $1193 \pm 319$ & $4987 \pm 2378$ & $5000 \pm 1240$ \\
\hline 0 & 0 & 0 & 0 & 0 & $100 \pm 17$ & $59 \pm 27$ & $1095 \pm 680$ & $2160 \pm 940$ \\
\hline 2 & $4 \pm 3$ & $4 \pm 3$ & 1 & 5 & $24 \pm 7$ & $18 \pm 6$ & $18 \pm 4$ & $21 \pm 8$ \\
\hline 491 & $1018 \pm 597$ & $942 \pm 510$ & 298 & 840 & $6942 \pm 2077$ & $5121 \pm 1854$ & $5286 \pm 1446$ & $6167 \pm 1312$ \\
\hline
\end{tabular}

1996; Vijayan, 1983; Kostovic, 1986; Zecevic and Verney, 1995; Arnold and Trojanowski, 1996; Hevner and Kinney, 1996; Berger et al., 2000). Therefore, the prenatal development of the three main neuronal populations and extrinsic inputs constitutes a substrate for a complex hippocampal network in utero.

\section{A GABA-glutamate sequence in the prenatal primate hippocampus}

From the early stages of development, immature hippocampal neurons start to establish synaptic connections and assemble the hippocampal network. The appearance of synaptic currents was
Figure 3. Sequential expression of GABA and glutamatergic synaptic currents correlated with the morphological differentiation of pyramidal cells. $A$, Three types of pyramidal cells are distinguished by synaptic responses to an electrical stimulation: a silent neuron that does not exhibit any synaptic activity (neuron 1 on Figs. 1 and $4 B$ ); a GABA-only neuron that displays exclusively bicuculline-sensitive GABA(A) receptor-mediated PSCs (neuron 2 on Figs. 1 and $4 C$ ); a GABA + glutamate neuron expressing both GABA and CNQX-sensitive glutamate receptormediated PSCs (neuron 3 on Figs. 1 and $4 D)$. Pyramidal cells were recorded in whole-cell mode at $-40 \mathrm{mV}$ (silent and GABA-only neurons) and at $-50 \mathrm{mV}$ (GABA + glutamate neuron). $B$, Morphometric parameters of silent, GABAonly, and GABA + glutamate pyramidal neurons, normalized to the near-term (E154) values. The silent neurons are the least differentiated cells. The GABAonly neurons display longer axonal and dendritic arbors than silent neurons. The GABA + glutamate neurons have significantly longer dendrites and axons than the two other groups. Note also that only GABA + glutamate neurons display dendritic spines. $C$, Age dependence of appearance of GABA(A) and glutamate receptor-mediated PSCs in pyramidal neurons.

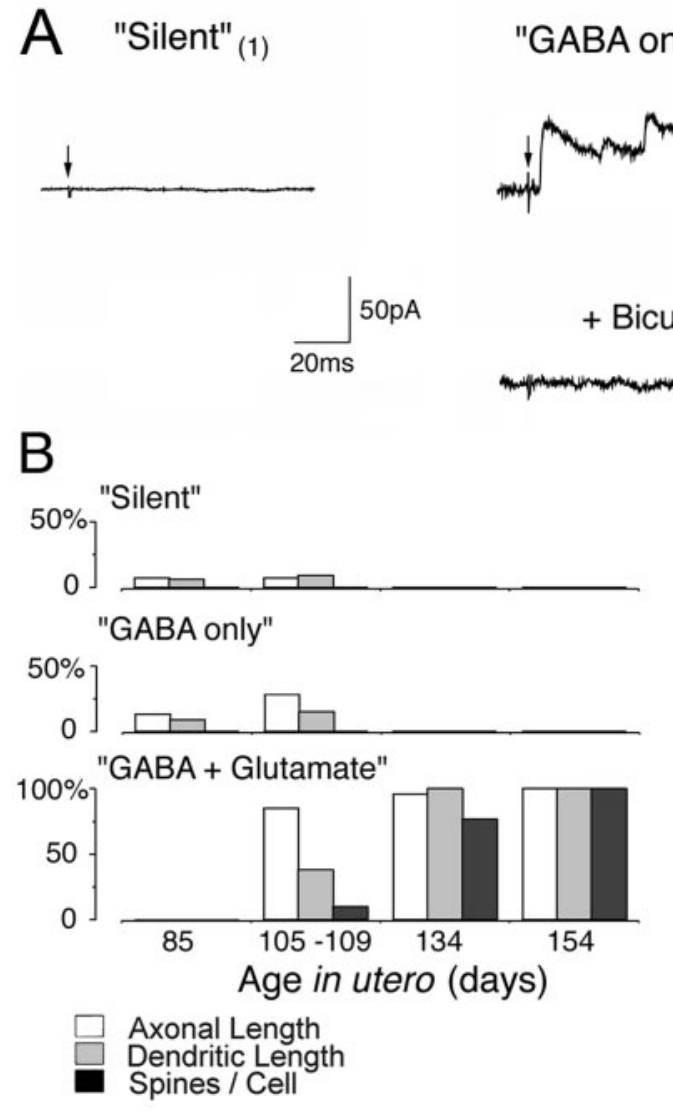

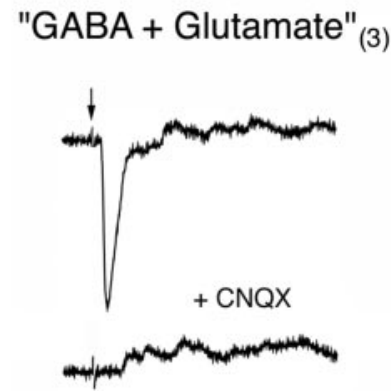

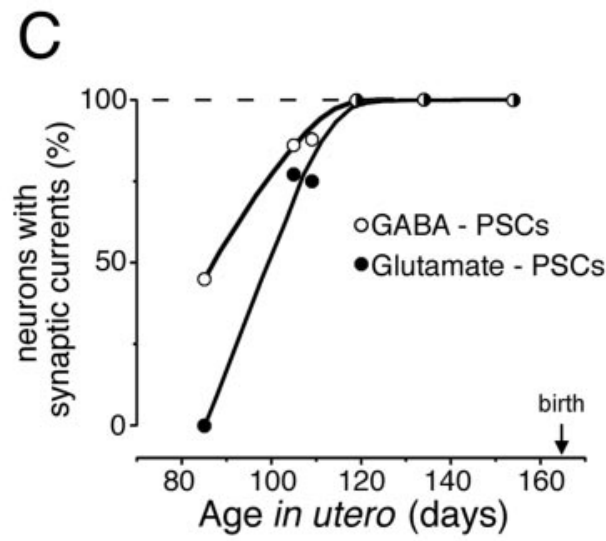




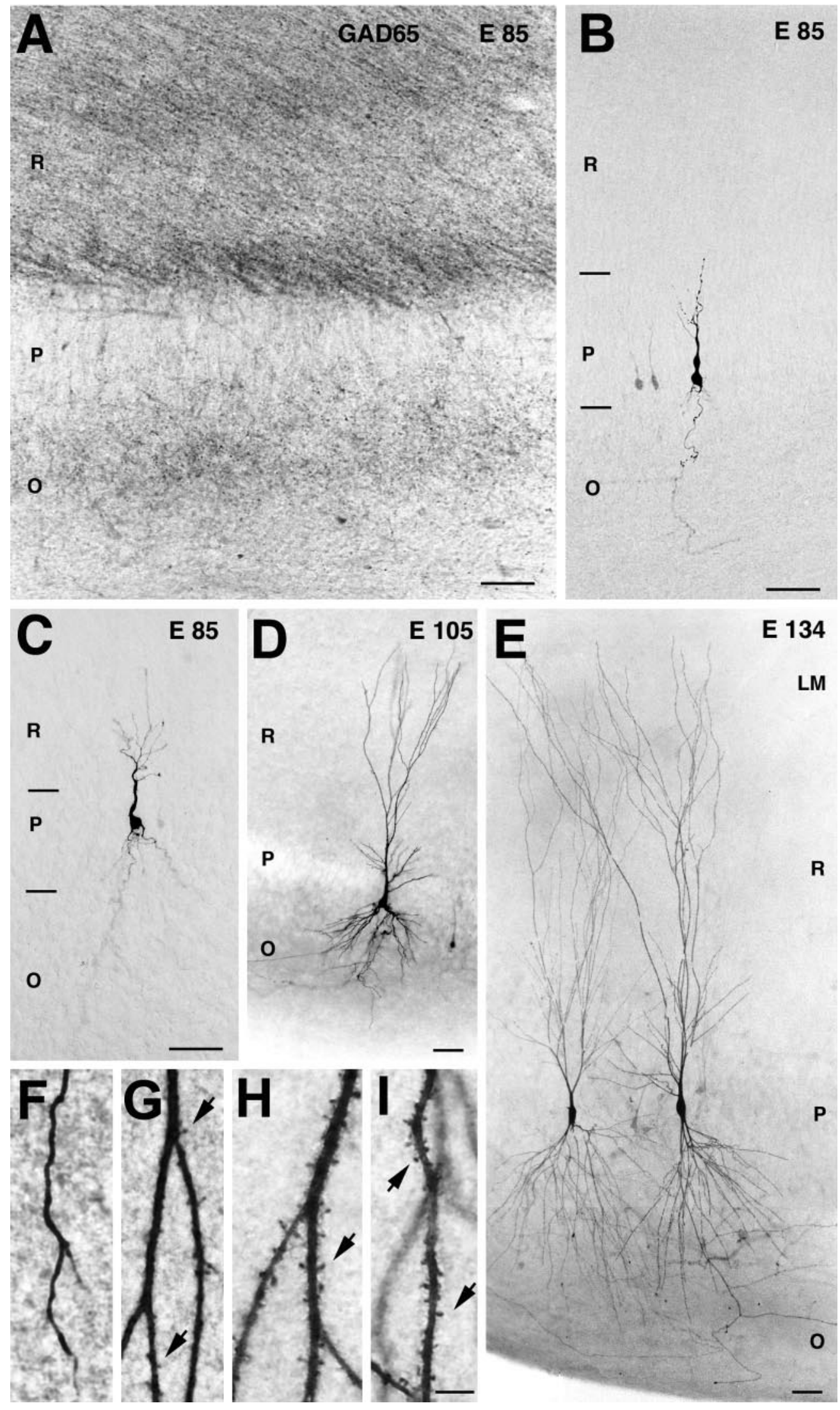

Figure 4. Morphological correlates of the early synapses on pyramidal cells. $A$, At E85, GABAergic terminals and fibers immunolabeled for GAD-65 are distributed in stratum radiatum $(R)$ and stratum oriens $(O)$ but not in stratum pyramidale $(P) . B-E$, Photomicrographs of pyramidal cells. $B$, A silent neuron from the CA1 region at E85, with its dendritic arbor restricted to stratum pyramidale. $C$, A GABA-only neuron from CA1 at E85, with apical dendrite penetrating into stratum radiatum. $D, E$, GABA + glutamate neurons, note the development of the dendritic arbor from E105 $(D)$ to E134 $(E) . F-I$, High magnification of dendritic processes of a GABA-only cell $(F)$ and GABA + glutamate neurons from E105 $(G)$, E134 $(H)$, and E154 $(I)$. Note that the emergence of glutamatergic PSCs coincides with the appearance of spines and that the number of spines increases with age. Scale bars: $A-E, 50 \mu \mathrm{m} ; F-I, 5 \mu \mathrm{m}$. 

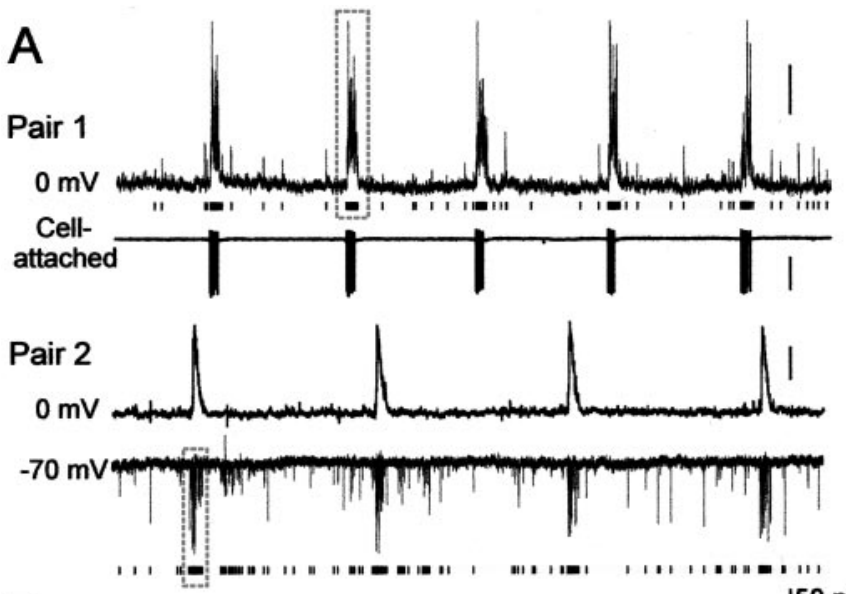

B

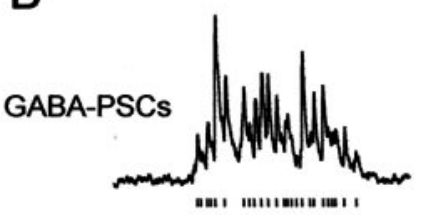

Glutamate-PSCs
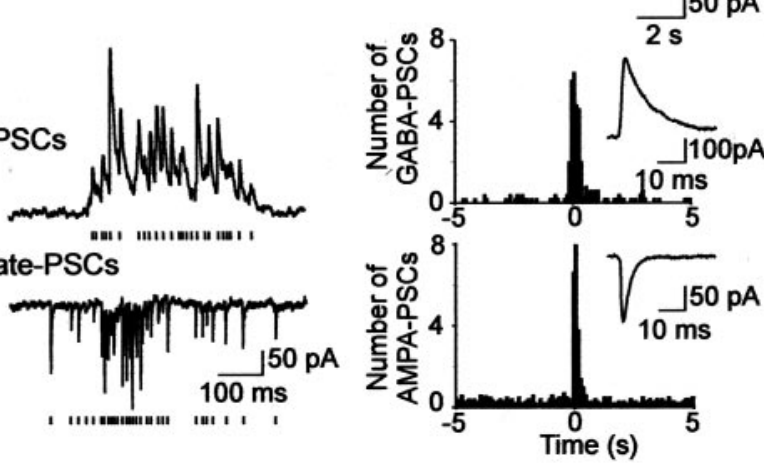

Figure 5. Giant depolarizing potentials synchronize most of the hippocampal neuronal activity in utero. A, Pair recordings of CA3 pyramidal cells and interneurons (E109). Pair 1, The pyramidal cell (top trace) is recorded in the whole-cell mode at the reversal potential of glutamatergic PSCs $(0 \mathrm{mV})$, and the GABA(A) PSCs are outwardly directed; the hilar interneuron (bottom trace) is recorded in the cell-attached mode. Each GABA(A) PSC detected in the pyramidal cell is shown as a bar below. Note the periodic oscillations (GDPs) synchronously generated in both neurons and associated with an increase of the GABA(A) PSC frequency in the pyramidal cell and bursts of action potentials in the interneuron. Pair 2, The pyramidal cell (top trace) is recorded in whole-cell mode at 0 $\mathrm{mV}$, and the interneuron (bottom trace) is recorded in whole-cell mode at the reversal potential of the GABA(A) PSCs $(-70 \mathrm{mV})$ so that the AMPA PSCs are inwardly directed. Each AMPA PSC detected in the interneuron is shown as a bar below. B, Left, GDPs outlined by dashed boxes on $A$ are shown on expanded time scale. Note an increase in the frequency of the GABA(A) and AMPA PSCs during GDPs. On the right, the distribution of GABA and AMPA PSCs is cross-correlated with the population discharge (bin size, $100 \mathrm{msec}$ ). Insets, Averaged GABA and AMPA PSCs.

highly correlated with a level of differentiation of the postsynaptic neuron and interestingly, the GABAergic synaptic currents in pyramidal cells preceded the glutamatergic ones, in keeping with results obtained in the postnatal rat hippocampus (Tyzio et al., 1999). The appearance of GABAergic synaptic currents coincided with development of apical dendrites and their penetration to stratum radiatum. Interestingly, dendritic-projecting GABAergic interneurons develop during the first half of gestation (Berger and Alvarez, 1996), whereas perisomatic-projecting interneurons develop later during the last third of gestation (Berger et al., 1999). In keeping with this, at midgestation, GABAergic terminals are present in strata radiatum and oriens but not in stratum pyramidale. Therefore, in primate, the first GABAergic synapses are likely formed on the apical dendrites of pyramidal cells in the proximal stratum radiatum, where the axons of the dendritic-

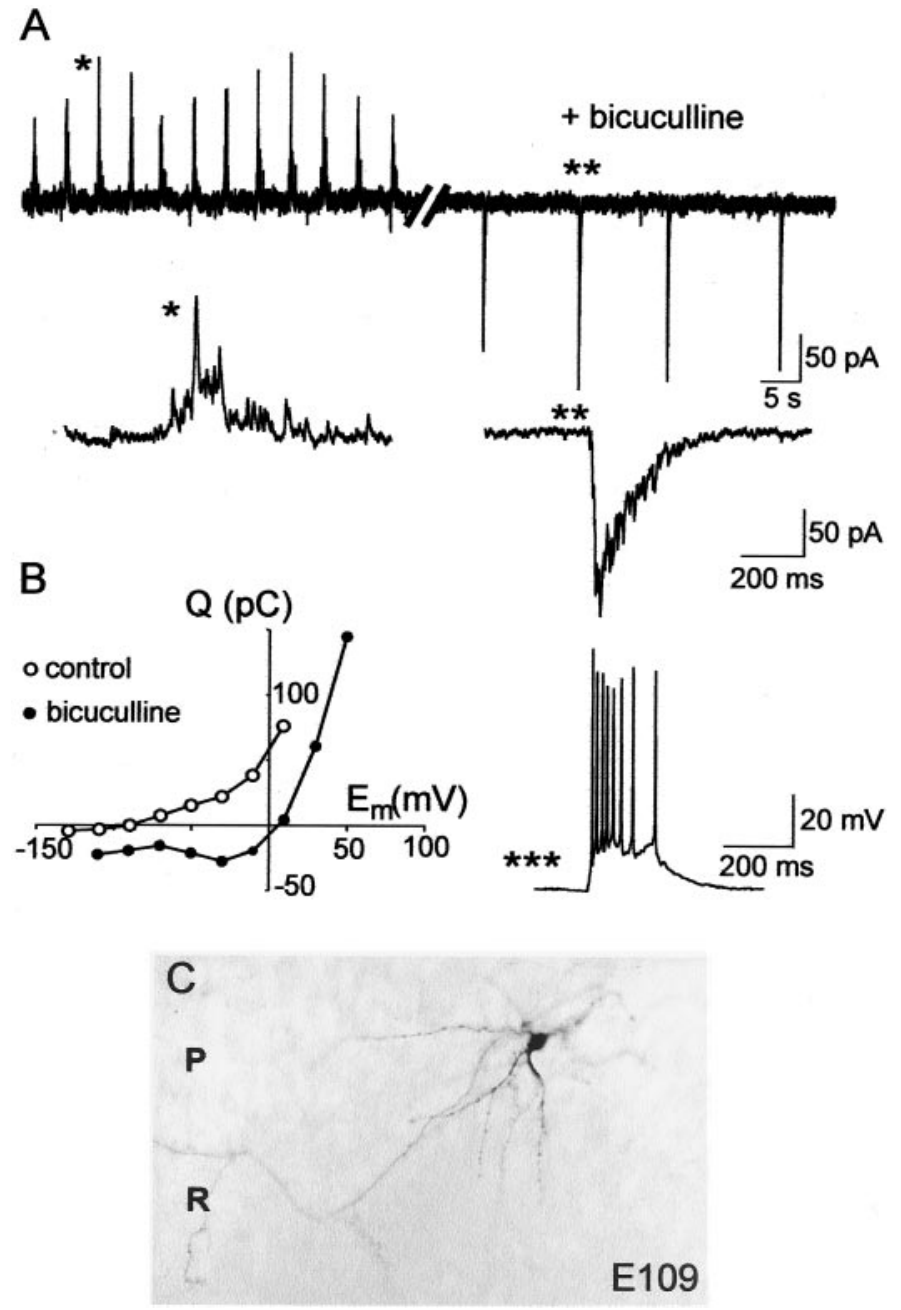

Figure 6. Blockade of GABA(A) receptors suppresses GDPs and induces an epileptiform activity. $A$, Spontaneous GDPs are transformed into interictal-like epileptiform events after addition of the GABA(A) receptor antagonist bicuculline. Whole-cell recordings of a stratum radiatum interneuron (E109) in voltage-clamp mode (holding potential, -50 $\mathrm{mV})$. Single GDP $(*)$ and interictal-like events $(* *)$ are shown on an expanded time scale below. In current-clamp mode, the interictal-like event generates burst of action potentials (***, resting potential $-72 \mathrm{mV}$ ). $B$, Charge-voltage relationships of GDPs and bicuculline-induced interictal-like events. Note that the charge-voltage curve of the epileptiform events reverses near $0 \mathrm{mV}$ and displays a negative slope at hyperpolarized potentials, suggesting a contribution of AMPA and NMDA receptors. $C$, Microphotograph of the recorded biocytin-labeled CA1 stratum radiatum interneuron.

projecting interneurons and growing apical dendrites of pyramidal cells meet. This paradigm is very similar to that described in neonatal rat hippocampus (Rozenberg et al., 1989; Soriano et al., 1989; Dupuy and Houser, 1996; Super et al., 1998; Tyzio et al., 1999).

The first glutamatergic synapses can be formed by intrinsic or extrinsic connections. Indeed, entorhinal (Hevner and Kinney, 1996) and supramammillary (Berger et al., 2000) afferents, mossy fibers of the granular cells (Berger and Alvarez, 1996), and pyramidal cell recurrent and Schaffer collaterals are already present when the first glutamatergic synaptic currents emerge. The observation that the glutamatergic currents participate in locally generated GDPs and paroxysmal activities suggest that they are intrinsic. The emergence of AMPA PSCs coincides with 
A

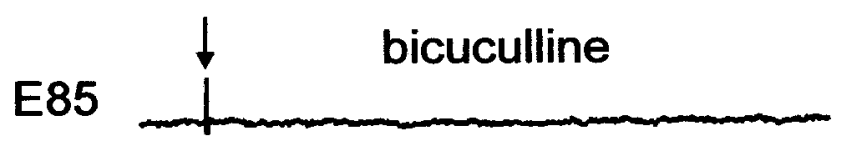

E105

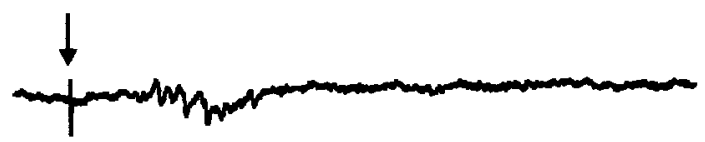

E109

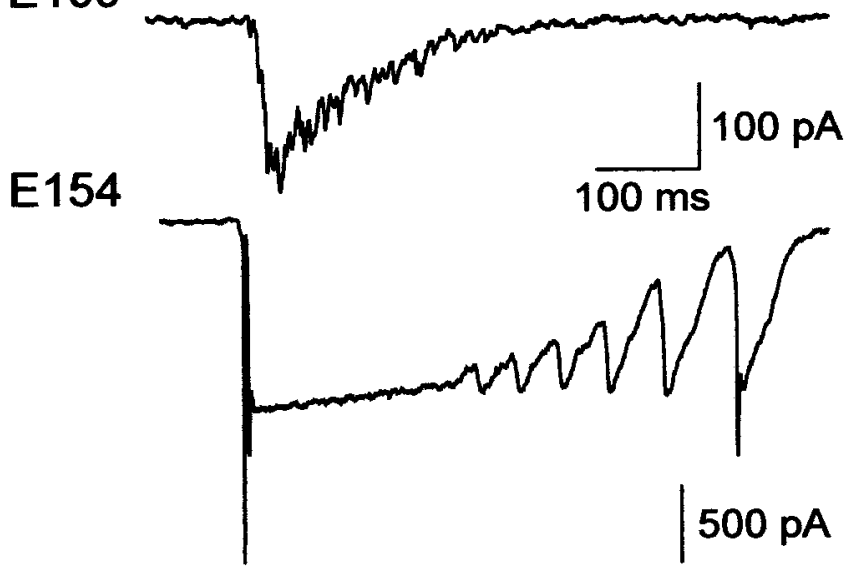

B

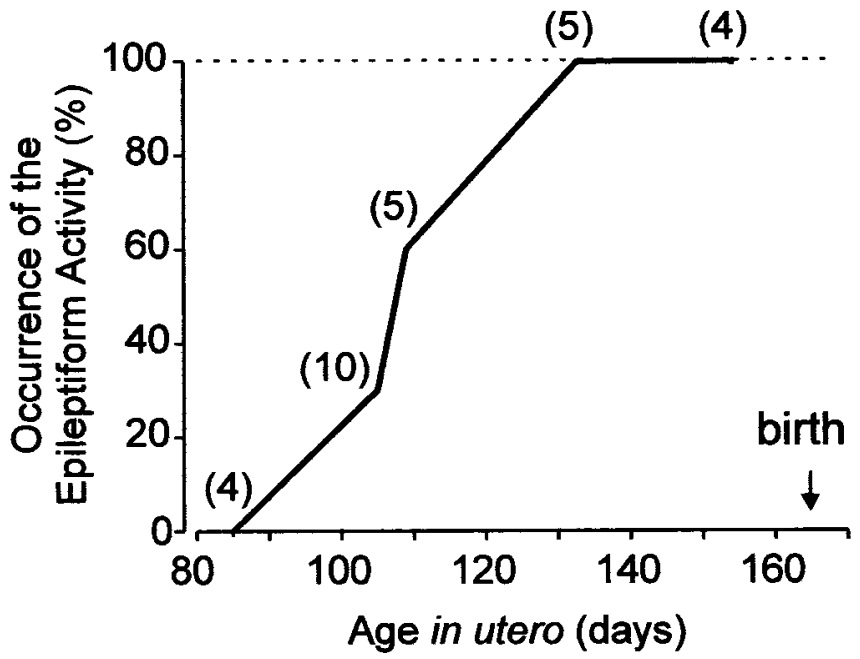

Figure 7. Developmental profile of epileptiform activity. A, Synaptic activity in CA3 pyramidal cells in the presence of bicuculline $(10 \mu \mathrm{M})$. At midgestation (E85), no seizure activity is observed; at E105, epileptiform events emerge and progress in occurrence and severity during the second half of gestation. Whole-cell recordings at holding potential of $-60 \mathrm{mV}$. At E85 and E105, the responses were evoked by electrical stimulation of the slice (marked by arrows); at E109 and E154, spontaneous interictallike events are shown. $B$, Plot summarizing the occurrence of the bicuculline-induced seizure activity in the fetal macaque hippocampal slices (number of cells). Note that all neurons express epileptiform activities from E134 onward.
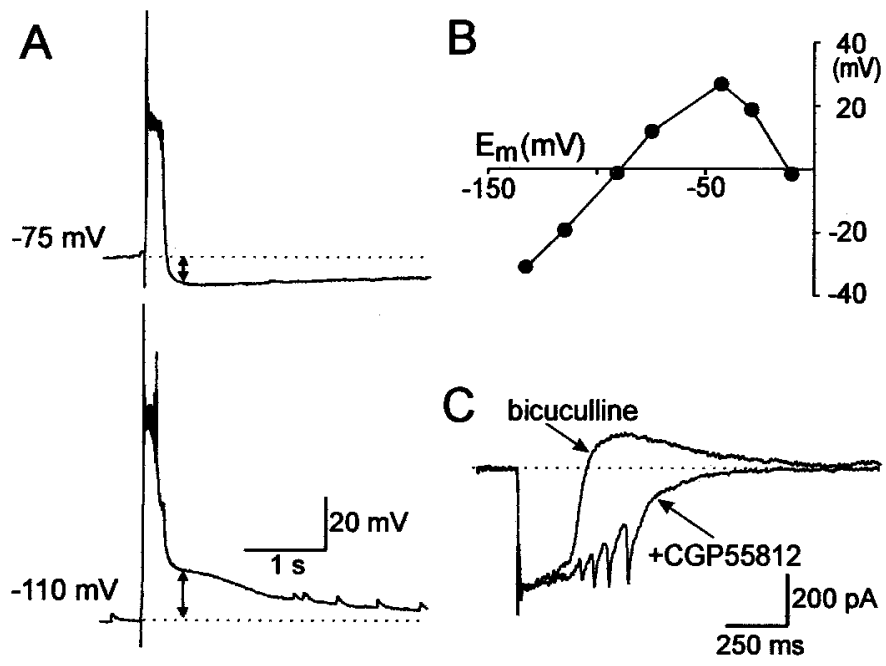

Figure 8. $\mathrm{GABA}(\mathrm{B})$ receptors contribute to the termination of bicuculline-induced epileptiform discharges. $A$, Bicuculline-induced epileptiform events in E134 CA3 pyramidal cell are curtailed by an afterhyperpolarization. Recordings in current-clamp mode at resting potential $(-75 \mathrm{mV}$; top trace) and at $-110 \mathrm{mV}$. B. Dependence of the afterdischarge hyperpolarization on membrane potential. Note the reversal potential at $-92 \mathrm{mV}$ and reduced amplitude at membrane potentials more positive than $-40 \mathrm{mV}$, a typical feature of the GABA(B) receptormediated potassium conductances. $C$, The GABA(B) receptor antagonist CGP55812 $(1 \mu \mathrm{M})$ blocks the curtailing outward current and significantly prolongs the epileptiform events. Whole-cell recording from E134 CA3 pyramidal cell in the voltage-clamp mode at holding potential of $-50 \mathrm{mV}$.

the appearance of mature dendritic spines. This correlates with the fact that although synaptogenesis is a dynamic process with many glutamatergic synapses formed on the dendritic shaft or immature spines (filopodia), functional synapses are mainly formed on mature spines (Edwards, 1995; Dailey and Smith, 1996; Ziv and Smith, 1996; Fiala et al., 1998; Rao et al., 1998; Luscher et al., 2000). Relying on the changes in the number of spines, it appears that hundreds of new glutamatergic synapses are formed each day on a pyramidal cell during the last third of gestation (Fig. 9).

\section{GDPs: a signature of developing hippocampus}

Most of the neuronal activity during the phase of intensive neuronal growth and synaptogenesis is synchronized in spontaneous network-driven discharges. Similarities between the fetal macaque and the neonatal rat network activities (Ben-Ari et al., 1989; Khazipov et al., 1997; Leinekugel et al., 1997; Strata et al., 1997; Bolea et al., 1999) suggest that GDPs represents a fundamental feature of the developing mammalian hippocampus. In the neonatal rat, the temporal window when the GDPs are observed coincides with a period when GABA depolarizes and excites the immature neurons (Ben-Ari et al., 1989; Khazipov et al., 1997; Leinekugel et al., 1997; Garaschuk et al., 1998). The presence of GDPs in the fetal monkey hippocampal slices suggests that GABA might be excitatory in the immature macaque hippocampal neurons; this however remains to be directly demonstrated. The physiological role of GDPs is presently unknown. In the rat, GDPs drive synchronous $\mathrm{Ca}^{2+}$ oscillations in the hippocampal neurons (Leinekugel et al., 1997; Garaschuk et al., 1998) and provide the conditions for Hebbian plasticity in the developing synapses (Hebb, 1949). It can therefore be suggested that GDPs participate in the activity-dependent formation of the hippocampal circuitry similarly to other internally generated spontaneous 

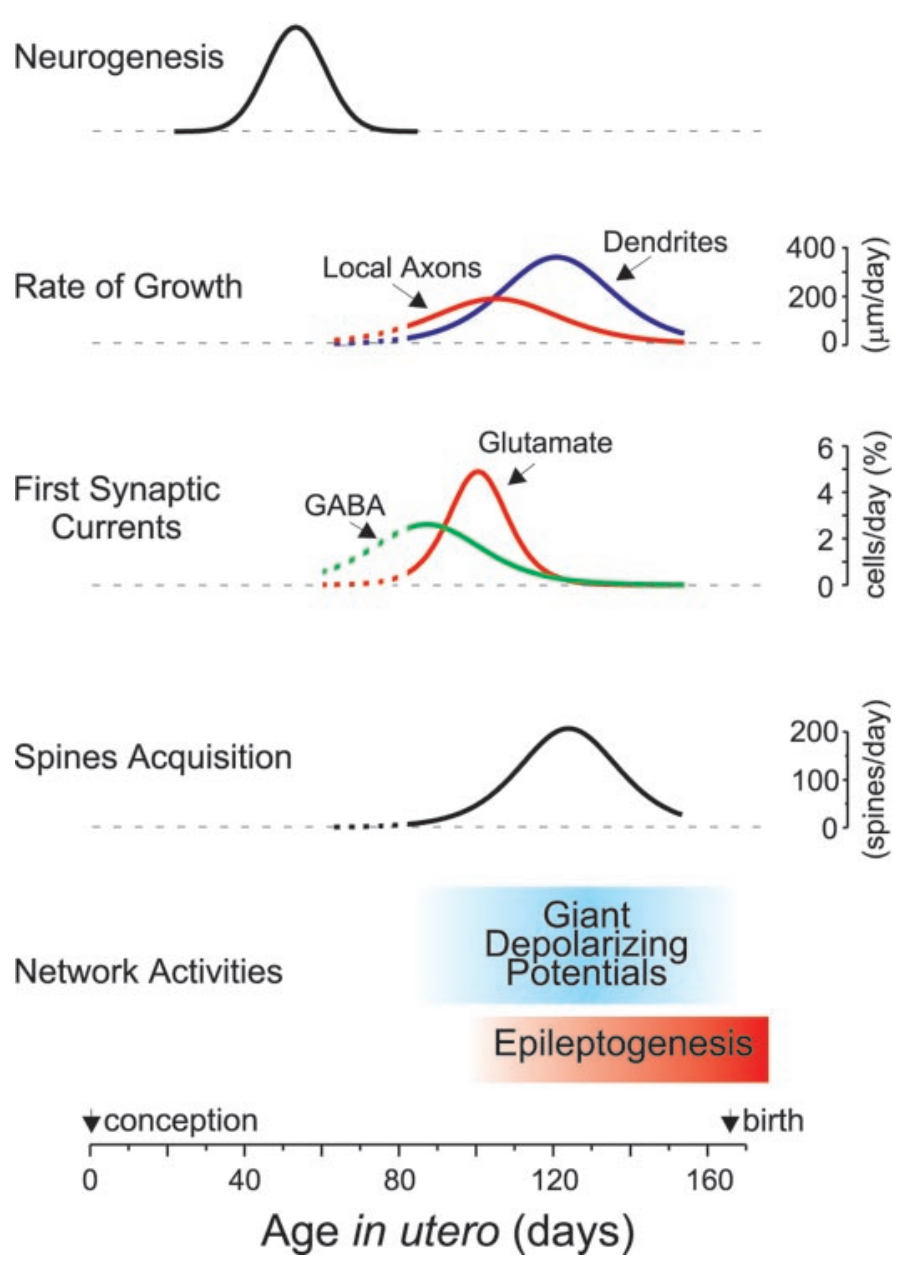

Figure 9. Developmental template of the fetal macaque hippocampus. Hippocampal neurons are generated during the first half of gestation, with a peak at E55. During the second half of gestation, pyramidal cells grow intensively with the maximal rate of axonal and dendritic growth attained at $\sim$ E105 and E120 (200 and $400 \mu \mathrm{m} / \mathrm{d}$ ), respectively. Already at midgestation (E85), half of the pyramidal cells receive GABAergic synaptic inputs. Glutamatergic synaptic currents appear later, and their expression coincides with the appearance of the first dendritic spines. The acquisition of glutamatergic synapses (as deduced from the number of dendritic spines) proceeds with a maximal rate of $\sim 200$ synapses formed every day on a pyramidal cell at $\sim$ E125. During the phase of intensive neuronal growth and synaptogenesis most of the neuronal activity is synchronized in a particular pattern of spontaneous network activity - the GDPs. By the last third of gestation, the hippocampal network also becomes capable of generating epileptiform activities. Data for the neurogenesis were taken from Rakic and Nowakowski (1981) and fitted with a Gaussian function. Rates of the axonal and dendritic growth, spine acquisition, and functional synapses formation were estimated by taking the first derivative of the Boltzmann fits in Figures 2 and $3 C$.

activities that have been observed in various developing brain structures before external input (Katz and Shatz, 1996; Ben-Ari, 2001).

\section{Epileptiform activity in the fetal primate}

EEG recordings indicate that paroxysmal activities can be generated in the neocortex of premature neonates (Hill, 2000) and can also be detected in utero using real-time ultrasound (Landy et al., 1989). The present study confirms these clinical observations and further demonstrates that in primate, the epileptiform activity can be generated in the hippocampus already in utero. This is important because clinical observations and animal studies have repeatedly demonstrated that epileptiform activities in the neonatal brain - often subclinical-can result in neurological and behavioral problems in adulthood, including reduction in the seizures threshold and development of temporal lobe epilepsy (Holmes and Ben-Ari, 1998). Thus, our study raises a concern about seizures that can potentially occur in the hippocampus already prenatally, during the last third of gestation. Interestingly, from the earliest developmental stages GABAergic interneurons inhibit the paroxysmal discharges. This is in agreement with the efficacy of positive GABA(A) receptor modulators for the treatment of seizures in neonates, including the premature neonates (Holmes, 1997). This is also in agreement with the data obtained in neonatal rats, in which GABAergic interneurons prevent the generation of paroxysmal activities from the early developmental stages via a shunting mechanism caused by the activation of GABA(A) receptors (Khalilov et al., 1999), the presynaptic inhibition of glutamate release, and the postsynaptic hyperpolarization mediated by GABA(B) receptors (McLean et al., 1996; Caillard et al., 1998).

\section{A developmental program that is maintained throughout evolution}

Comparing early developmental events in the rat and macaque, it appears that the general developmental scenario is very similar in these two species but with a general shift toward fetal life in primates (Fig. 9). In the rat hippocampus, the neurogenesis of pyramidal cells proceeds during the last third of embryonic life, at E16-E20 (Bayer, 1980) and in the rhesus macaque during the first half of gestation, at E38-E80 (Rakic and Nowakowski, 1981). At birth (E22 in the rat), the hippocampal pyramidal cells attain a level of maturity and synaptic inputs (Tyzio et al., 1999) comparable with that achieved in the monkey at midgestation. Boltzmann fits of the morphometric data obtained in the rat reveal that the rate of axonal growth peaks at postnatal day 7 (P7) (Gomez-Di Cesare et al., 1997) (in macaque: E109), the dendritic growth peaks at P9 (Minkwitz, 1976) (in macaque: E120), and the spinogenesis peaks at P16 (Englisch et al., 1974; Minkwitz, 1976; Bannister and Larkman, 1995) (in macaque: E125). GDPs are present in rat hippocampal slices from birth to P12-P16 (Ben-Ari et al., 1989; Garaschuk et al., 1998) whereas in the macaque, they dominate during the last third of gestation and decrease before birth. Epileptiform activities emerge in rat hippocampus during the first postnatal week, and the peak of epileptogenesis falls in the second and third postnatal weeks (Khalilov et al., 1999; Swann et al., 1999; Wells et al., 2000), whereas in the macaque, epileptiform activity builds up during the last third of gestation and can also progress postnatally. Thus, the template of sequential expression of the developmental processes, including neuronal growth, synaptogenesis, and expression of network activities are very similar in the rodent and primate. This suggests that the template of early hippocampal development is conserved throughout mammalian evolution. Furthermore, its prenatal expression in primate suggests that this process is independent of external stimuli and is rather inherent as it has been shown for the development of visual cortex (Rakic, 1976).

\section{Neuropsychological aspects}

Our study suggests that a complex hippocampal network capable of generating synchronized activities already exists in utero in nonhuman primate and may provide a substrate for early behavioral functions. Indeed, in spite of the general belief that the behavioral functions of the hippocampus emerge later in infants 
because of the amnesia of the first years of human life (Nadel and Zola-Morgan, 1984), recent neuropsychological studies have provided evidence of the emergence of a hippocampal-dependent form of recognition memory early after birth (Bachevalier et al., 1993; Bachevalier and Mishkin, 1994; Pascalis and de Schonen, 1994; Pascalis and Bachevalier, 1999). The results of the present study add morphofunctional support to these observations.

\section{REFERENCES}

Arnold SE, Trojanowski JQ (1996) Human fetal hippocampal development: I. Cytoarchitecture, myeloarchitecture, and neuronal morphologic features. J Comp Neurol 367:274-292.

Bachevalier J, Mishkin M (1994) Effects of selective neonatal temporal lobe lesions on visual recognition memory in rhesus monkeys. J Neurosci 14:2128-2139.

Bachevalier J, Brickson M, Hagger C (1993) Limbic-dependent recognition memory in monkeys develops early in infancy. NeuroReport 4:77-80.

Bannister NJ, Larkman AU (1995) Dendritic morphology of CA1 pyramidal neurones from the rat hippocampus: II. Spine distributions. J Comp Neurol 360:161-171.

Bayer SA (1980) Development of the hippocampal region in the rat. II. Morphogenesis during embryonic and early postnatal life. J Comp Neurol 190:115-134.

Ben-Ari Y (2001) Developing networks play a similar melody. Trends Neurosci 24:353-360.

Ben-Ari Y, Cherubini E, Corradetti R, Gaiarsa JL (1989) Giant synaptic potentials in immature rat $\mathrm{CA} 3$ hippocampal neurones. J Physiol (Lond) 416:303-325.

Berger B, Alvarez C (1996) Neurochemical development of the hippocampal region in the fetal rhesus monkey. III: Calbindin-D28K, calretinin and parvalbumin with special mention of Cajal-Retzius cells and the retrosplenial cortex. J Comp Neurol 366:674-699.

Berger B, Alvarez C, Pelaprat D (1997) Retrosplenial/presubicular continuum in primates: a developmental approach in fetal macaques using neurotensin and parvalbumin as markers. Brain Res Dev Brain Res 101:207-224.

Berger B, De Grissac N, Alvarez C (1999) Precocious development of parvalbumin-like immunoreactive interneurons in the hippocampal formation and entorhinal cortex of the fetal cynomolgus monkey. J Comp Neurol 403:309-331.

Berger B, Esclapez M, Alvarez C, Meyer G, Catala M (2000) Human and monkey fetal brain development of the supramammillaryhippocampal projections: A system involved in the regulation of theta rhythm activity. J Comp Neurol 429:515-529.

Bolea S, Avignone E, Berretta N, Sanchez-Andres JV, Cherubini E (1999) Glutamate controls the induction of GABA-mediated giant depolarizing potentials through AMPA receptors in neonatal rat hippocampal slices. J Neurophysiol 81:2095-2102.

Caillard O, McLean HA, Ben-Ari Y, Gaiarsa JL (1998) Ontogenesis of presynaptic $\mathrm{GABAB}$ receptor-mediated inhibition in the $\mathrm{CA} 3$ region of the rat hippocampus. J Neurophysiol 79:1341-1348.

Dailey ME, Smith SJ (1996) The dynamics of dendritic structure in developing hippocampal slices. J Neurosci 16:2983-2994.

Duffy CJ, Rakic P (1983) Differentiation of granule cell dendrites in the dentate gyrus of the rhesus monkey: a quantitative Golgi study. J Comp Neurol 214:224-237.

Dupuy ST, Houser CR (1996) Prominent expression of two forms of glutamate decarboxylase in the embryonic and early postnatal rat hippocampal formation. J Neurosci 16:6919-6932.

Eckenhoff MF, Rakic P (1991) A quantitative analysis of synaptogenesis in the molecular layer of the dentate gyrus in the rhesus monkey. Brain Res Dev Brain Res 64:129-135.

Edwards FA (1995) Anatomy and electrophysiology of fast central synapses lead to a structural model for long-term potentiation. Physiol Rev 75:759-787.

Englisch HJ, Kunz G, Wenzel J (1974) Distribution of spines on the pyramidal neurons in the CA-1 region of the hippocampus in the rat. $\mathrm{Z}$ Mikrosk Anat Forsch 88:85-102.

Esclapez M, Tillakaratne NJ, Kaufman DL, Tobin AJ, Houser CR (1994) Comparative localization of two forms of glutamic acid decarboxylase and their mRNAs in rat brain supports the concept of functional differences between the forms. J Neurosci 14:1834-1855.

Esclapez M, Dinocourt C, Ben-Ari Y, Berger B (1999) Developmental changes of GABA interneurons in the fetal hippocampal formation in the cynomolgus monkey. Soc Neurosci Abstr 29:2266.

Fiala JC, Feinberg M, Popov V, Harris KM (1998) Synaptogenesis via dendritic filopodia in developing hippocampal area CA1. J Neurosci 18:8900-8911.

Freund TF, Buzsaki G (1996) Interneurons of the hippocampus. Hippocampus 6:347-470.
Fukuda A, Mody I, Prince DA (1993) Differential ontogenesis of presynaptic and postsynaptic GABAB inhibition in rat somatosensory cortex. J Neurophysiol 70:448-452.

Gaiarsa JL, McLean H, Congar P, Leinekugel X, Khazipov R, Tseeb V, Ben-Ari Y (1995) Postnatal maturation of gamma-aminobutyric acidA and B-mediated inhibition in the CA3 hippocampal region of the rat. J Neurobiol 26:339-349.

Garaschuk O, Hanse E, Konnerth A (1998) Developmental profile and synaptic origin of early network oscillations in the CA1 region of rat neonatal hippocampus. J Physiol (Lond) 507:219-236.

Gomez-Di Cesare CM, Smith KL, Rice FL, Swann JW (1997) Axonal remodeling during postnatal maturation of CA3 hippocampal pyramidal neurons. J Comp Neurol 384:165-180.

Hebb DO (1949) The organization of behaviour. New York: Wiley.

Hevner RF, Kinney HC (1996) Reciprocal entorhinal-hippocampal connections established by human fetal midgestation. J Comp Neurol 372:384-394.

Hill A (2000) Neonatal seizures. Pediatr Rev 21:117-121.

Hirsch JC, Quesada O, Esclapez M, Gozlan H, Ben-Ari Y, Bernard CL (1996) Enhanced NMDAR-dependent epileptiform activity is controlled by oxidizing agents in a chronic model of temporal lobe epilepsy. J Neurophysiol 76:4185-4189.

Holmes GL (1997) Epilepsy in the developing brain: lessons from the laboratory and clinic. Epilepsia 38:12-30.

Holmes GL, Ben-Ari Y (1998) Seizures in the developing brain: perhaps not so benign after all. Neuron 21:1231-1234.

Humphrey T (1967) The development of the human hippocampal fissure. J Anat 101:655-676.

Katz LC, Shatz CJ (1996) Synaptic activity and the construction of cortical circuits. Science 274:1133-1138.

Khalilov I, Dzhala V, Ben-Ari Y, Khazipov R (1999) Dual role of GABA in the neonatal rat hippocampus. Dev Neurosci 21:310-319.

Khazipov R, Leinekugel X, Khalilov I, Gaiarsa JL, Ben-Ari Y (1997) Synchronization of GABAergic interneuronal network in CA3 subfield of neonatal rat hippocampal slices. J Physiol (Lond) 498:763-772.

Kostovic I (1986) Prenatal development of nucleus basalis complex and related fiber systems in man: a histochemical study. Neuroscience 17:1047-1077.

Kostovic I, Seress L, Mrzljak L, Judas M (1989) Early onset of synapse formation in the human hippocampus: a correlation with Nissl-Golgi architectonics in 15- and 16.5-week-old fetuses. Neuroscience 30:105-116.

Landy HJ, Khoury AN, Heyl PS (1989) Antenatal ultrasonographic diagnosis of fetal seizure activity. Am J Obstet Gynecol 161:308.

Leinekugel X, Medina I, Khalilov I, Ben-Ari Y, Khazipov R (1997) $\mathrm{Ca}^{2+}$ oscillations mediated by the synergistic excitatory actions of GABA(A) and NMDA receptors in the neonatal hippocampus. Neuron 18:243-255.

Luscher C, Nicoll RA, Malenka RC, Muller D (2000) Synaptic plasticity and dynamic modulation of the postsynaptic membrane. Nat Neurosci 3:545-550.

McLean HA, Caillard O, Khazipov R, Ben-Ari Y, Gaiarsa JL (1996) Spontaneous release of GABA activates GABAB receptors and controls network activity in the neonatal rat hippocampus. J Neurophysio 76:1036-1046.

Minkwitz HG (1976) Development of neuronal structure in the hippocampus during pre- and post-natal ontogenesis in the albino rat. III. Morphometric determination of ontogenetic changes in dendrite structure and spine distribution on pyramidal neurons (CA1) of the hippocampus. J Hirnforsch 17:255-275.

Nadel L, Zola-Morgan S (1984) Infantile amnesia: a neurobiological perspective. In: Infant memory (Moscovitch M, ed), pp145-172. New York: Plenum.

Nowakowski RS, Rakic P (1979) The mode of migration of neurons to the hippocampus: a Golgi and electron microscopic analysis in foetal rhesus monkey. J Neurocytol 8:697-718.

Paldino AM, Purpura DP (1979) Branching patterns of hippocampal neurons of human fetus during dendritic differentiation. Exp Neurol 64:620-631.

Pascalis O, Bachevalier J (1999) Neonatal aspiration lesions of the hippocampal formation impair visual recognition memory when assessed by paired-comparison task but not by delayed nonmatching-to-sample task. Hippocampus 9:609-616.

Pascalis O, de Schonen S (1994) Recognition memory in 3- to 4-day-old human neonates. NeuroReport 5:1721-1724.

Rakic P (1976) Prenatal genesis of connections subserving ocular dominance in the rhesus monkey. Nature 261:467-471.

Rakic P, Nowakowski RS (1981) The time of origin of neurons in the hippocampal region of the rhesus monkey. J Comp Neurol 196:99-128.

Rao A, Kim E, Sheng M, Craig AM (1998) Heterogeneity in the molecular composition of excitatory postsynaptic sites during development of hippocampal neurons in culture. J Neurosci 18:1217-1229.

Rozenberg F, Robain O, Jardin L, Ben-Ari Y (1989) Distribution of GABAergic neurons in late and early postnatal rat hippocampus. Dev Brain Res 50:177-187. 
Seress L, Ribak CE (1995) Postnatal development of CA3 pyramidal neurons and their afferents in the Ammon's horn of rhesus monkeys. Hippocampus 5:217-231.

Soriano E, Cobas A, Fairen A (1989) Neurogenesis of glutamic acid decarboxylase immunoreactive cells in the hippocampus of the mouse. II. Area dentata. J Comp Neurol 281:603-611.

Strata F, Atzori M, Molnar M, Ugolini G, Tempia F, Cherubini E (1997) A pacemaker current in dye-coupled hilar interneurons contributes to the generation of giant GABAergic potentials in developing hippocampus. J Neurosci 17:1435-1446.

Super H, Martinez A, Del Rio JA, Soriano E (1998) Involvement of distinct pioneer neurons in the formation of layer-specific connections in the hippocampus. J Neurosci 18:4616-4626.

Swann JW, Pierson MG, Smith KL, Lee CL (1999) Developmental neuroplasticity: roles in early life seizures and chronic epilepsy. Adv Neurol 79:203-216.
Tyzio R, Represa A, Jorquera I, Ben-Ari Y, Gozlan H, Aniksztejn L (1999) The establishment of GABAergic and glutamatergic synapses on CA1 pyramidal neurons is sequential and correlates with the development of the apical dendrite. J Neurosci 19:10372-10382.

Vijayan VK (1983) Prenatal and postnatal development of synapses and acetylcholinesterase staining in the dentate gyrus of the rhesus monkey. Int J Dev Neurosci 1:77-97.

Vijayan VK (1986) Morphogenesis of the mossy fiber synapses in the hippocampus of the rhesus monkey. Brain Res 390:259-270.

Wells JE, Porter JT, Agmon A (2000) GABAergic inhibition suppresses paroxysmal network activity in the neonatal rodent hippocampus and neocortex. J Neurosci 20:8822-8830.

Zecevic N, Verney C (1995) Development of the catecholamine neurons in human embryos and fetuses, with special emphasis on the innervation of the cerebral cortex. J Comp Neurol 351:509-535.

Ziv NE, Smith SJ (1996) Evidence for a role of dendritic filopodia in synaptogenesis and spine formation. Neuron 17:91-102. 